\title{
LA INTERPRETACIÓN DEL PATRIMONIO EN EL SUR DE CHILE: UN ENFOQUE PARA EL TURISMO DE INTERESES ESPECIALES EN LA PATAGONIA
}

\author{
Juan Carlos Castaing von der Hundt \\ Miembro Asociación de Interpretación del Patrimonio (AIP) \\ Técnico en Turismo \\ Departamento de Gobierno y Empresa \\ Universidad de Los Lagos \\ Guillermo Pacheco Habert \\ Mg. Ciencias Sociales \\ Lic. Administración de Empresas de Turismo \\ Departamento de Gobierno y Empresa \\ Universidad de Los Lagos
}

\section{Resumen}

Este ensayo busca ser una referencia para que la Interpretación del Patrimonio (IP) pueda ser considerada en las estrategias y planes de desarrollo turístico de la Región de Los Lagos y en territorios de prioritario interés para la planificación turística de destinos turísticos como lo es Patagonia Verde. Se identifican las barreras de la IP en las principales áreas naturales protegidas de la Región de Los Lagos y aquellas experiencias que han aplicado técnicas de la IP en el desarrollo de nuevos productos turísticos. A la vez, se proponen principios para el desarrollo de planes de IP en la región y, finalmente, se generan distintas conclusiones útiles para considerar en las políticas públicas o estrategias de desarrollo local involucradas en el patrimonio cultural y natural de uso turístico.

Palabras clave: Interpretación del Patrimonio, Planificación Turística, Patagonia. 


\title{
HERITAGE INTERPRETATION IN SOUTH OF CHILE: AN APROACH FROM SPECIAL INTEREST TOURISM IN PATAGONIA.
}

\author{
Juan Carlos Castaing von der Hundt \\ Miembro Asociación de Interpretación del Patrimonio (AIP) \\ Técnico en Turismo \\ Departamento de Gobierno y Empresa \\ Universidad de Los Lagos \\ Guillermo Pacheco Habert \\ Mg. Ciencias Sociales \\ Lic. Administración de Empresas de Turismo \\ Departamento de Gobierno y Empresa \\ Universidad de Los Lagos
}

\begin{abstract}
Methodologies applied in Heritage Interpretation nowadays has been created to develop effective strategies in the use of messages, such as themed content for guided visits, or creating more analysis to develop relevant and organized messages to the audience (or visitor). Sometimes in management and planning concepts, used in tourism industry, we can find elements coming from social science and local economic development, organized in a human scale impact, as a phenomenological approach. The concept of Heritage Interpretation in some territories, like Patagonia and the Lake District in Chile need to be organized in three scales; community base planning, integrated planning and endogenous development. This is to identify a more effective methodology to create several Master Plans in sites and local attractions, and understand how locals has been using these Heritage Interpretation principles, tools and techniques along the time.
\end{abstract}

Keywords: Heritage interpretation, Tourism Planning and Patagonia. 


\section{Introducción}

La Interpretación del Patrimonio nació como una necesidad humana pretérita que es más antigua que la misma definición. Se puede remontar a un aspecto cultural y humano muy básico, pero no menos complejo; el que busca unir y crear las conexiones vitales entre el legado de la humanidad y su entorno eco-social. Por lo que no es un conocimiento excluyente de un campo académico, ni de la gestión o planificación turística y patrimonial. Debería también abarcar tanto a la ética patrimonial, los saberes locales, el desarrollo comunitario como otros aspectos filosóficos y psicológicos que implican los diversos y complejos protocolos de comunicación con visitantes y residentes. Desde ésta perspectiva holística del conocimiento, cada individuo puede involucrarse en esta búsqueda, por derecho propio, en el contexto de su espacio y de su tiempo determinado, vinculándose a esta herencia que le fue concedida por una cultura y por el solo derecho de haber nacido en este planeta. Por lo tanto no todos hacen interpretación patrimonial, pero sí cualquiera bajo el adecuado manejo de sus técnicas puede llegar a realizarla de manera efectiva y eficaz.

Freeman Tilden, dramaturgo, periodista y filósofo, poseía una profunda intuición acerca de cómo los humanos podemos comunicarnos mejor desde la perspectiva de lo que es más trascendente. Hacia la década del 50, Tilden comienza a trabajar para el Servicio de Parques Nacionales de Estados Unidos, con el fin de controlar el turismo masivo y cambiar las normas restrictivasyrepresorasporotrasquemotivaranalosvisitantesatenerunamejorrelaciónconel ambiente (Fernández et al., 2007).

Para el mundo hispanoparlante, y específicamente para Latinoamérica, el término IP ha sido acuñado como propio, siendo muy coherente para trabajar el Turismo de Intereses Especiales (TIE), debido a su particularidad de fortalecer el relato de los guías turísticos y visibilizar la identidad de territorios más vulnerables en lo patrimonial, utilizando conceptos comunicacionales integrales, también aplicados en planificación turística. Para Tilden no era oportunoprohibirparaprotegerelpatrimonionaturalatravésdeseñaléticasquecomienzancon la palabra "No", sino que todo lo contrario, comunicar a través de señaléticas o paneles interpretativos mensajes que revelen significados y desarrollen conductas de mayor respeto y cuidado con el patrimonio ambiental y cultural observado.

Son las mismas palabras de Tilden las que nos orientan en la idea de que su trabajo observaba el fenómeno de cada ser humano como el de un ser integral y espiritual en sí, en una búsqueda porencontrarunaalquimiaelementalobajo loqueactualmentesecomprendecomoelfenómeno del insight acuñado ampliamente en la sicología de la Gestalt, sicología transpersonal y en Programación Neuro Lingüística(PNL): "Los primeros filósofos griegos miraron el mundoa sualrededoryencontraronquehabíacuatroelementos:fuego, aire, aguaytierra.Peroamedida 
quecrecíanensabiduríaconsiderabanquedebíahaberalgomás, elquintoelemento, compuesto de elementos no tangibles que no constituyen un principio, sino que simplemente se revela que están en otro lugar. Si no los encuentras, no existe el alma de las cosas, una quinta esencia, pura, eterna e incluyente" (Tilden 1957, traducción propia).

Este trasfondo es la idea de "legado" (más cercano al inglés heritage) que Tilden nos logra entregarenlasreflexionesypublicacionesalolargodesuhistoria. Esloqueposteriormentenos ayuda a definir el sustrato de lo verdaderamente patrimonial, la base de una herencia cultural, quees un aspecto integral que se acerca más a lo intangibley losimbólico,y que facilita tantoal intérprete como a la audiencia ese camino al mar del asombro. De esta forma se logra la comunicación entre sí y el encuentro con lo más preciado del legado como resultado de una búsquedacolectiva. Esdesdeaquíquepodemosdecirconmuchofundamentoqueentregaruna interpretación no es lo mismo que solo entregar información (Tilden, 1957), lo que es una distinciónimportantequesepuedeencontrartantoenlatécnicadelaIPcomoenlaintenciónde quién la aplica, siendo un aspecto diferenciador clave en el diálogo entre las ciencias duras y el arte, que por excelencia interpreta desde una escala humana y holística.

EsasícomoFernándezBalboa(2007)serefierealmalusodelconcepto, expresando: "Conuna aplicación excesivamentepragmáticay conun escaso desarrolloteórico corremoselriesgode que el término "interpretación" sufra la misma suerte que siguió la palabra "ecología", que se popularizó y mercantilizó en la década del 80; por aquel entonces los pañales ecológicos, las tintorerías ecológicas y otros productos teñidos de marketing verde desvirtuaban el significado del término, que no es otra cosa que una rama de las ciencias naturales. Vaciar de significado la palabra interpretación generaría un perjuicio para quienes trabajan auténticamente con los principios de la disciplina, ya que si cualquier actividad con un poco de "ritmo" y "color" es “interpretativa”, nada termina siéndolo" (Fernández et al., 2007:14).

Bajolamismareflexiónanterior,lapalabraecoturismotambiénhasidocuestionada;comobien dice Boullon (2003), el ecoturismo no nace con el invento de la palabra, sino que desde muchoanteshubounsegmentoqueviajóporelmundoparaobservarlanaturaleza.Porejemplo, aquí lo importante es entender que el marketing turístico responde a diversos objetivos y tendencias, pero cuando se realiza desde la IPy se conceptualiza el desarrollo de un marketing para elTIE debe ser guardando el principioético de que sufin es educar, conservar, regenerary ponerenvalorel patrimoniouniversal,comotambiénrespetaralascomunidadeslocalesyalas otras dimensiones del mismo patrimonio observado.

LaIPesentendidacomounprocesodecomunicaciónquerevelalaimportanciayelsignificado delpatrimonioculturalynaturaldeunaformaqueserelacioneconlaspropiasexperienciasdelos visitantes, estimulandosuinterésy ampliandosus horizontes(Hamish,2009; Morales, 2001). 
Es fundamental conocer las características de la audiencia a la cual se buscallamar la atención ydespertarelinterés, siendoestrategias distintaslasquelograncaptaraniñosoadultos(Torres, 2012); por otra parte, los procesos de comunicación en la IP tienden a modernizarse y cada vez másasermásinteractivosenelcontextoculturalenqueseaplican.Enesesentido,laexperiencia sensorialquesedeseaofrecerenlosdestinosturísticosrespondeaunasituacióninteractivaenla que existe retroalimentación entre el visitante y el patrimonio (Torres, 2012). Aspecto que se vislumbra como una clara necesidad de los destinos turísticos de la Región de Los Lagos y en Patagonia Verde, que poseen barreras en la promoción, difusión e interpretación de su patrimonio de uso turístico. Aquí encontramos la oportunidad que tiene para el TIE mejorar la experiencia del visitante, mediante una comunicación que sea temática, pero que también emocione y provoque a los viajeros y que lo haga desde las experiencias auténticas que involucran al patrimonio cultural y natural del territorio.

Comprendemos el TIE como "una modalidad de turismo que incluye al turismo aventura, ecoturismo, turismo rural, turismo cultural, agroturismo, turismo comunitario y vivencial, etc.; se dirige hacia una demanda selectiva y está estrechamente relacionado con la naturaleza y la cultura de un territorio. El TIE se contrapone a lo que conocemos por turismo de enclave o turismo de sol y playa, pues estos muchas veces no llevan en cuenta los costos socioambientales y socioculturales, dejando en segundo plano los beneficios y la participación de los residentes locales. Se diferencia de otros tipos de turismo por atraer una demanda selectiva de turistas conscientes, entendidos en las temáticas o prácticas desarrolladas en los destinos a visitar, como también un número de demanda controlada relativamente baja o normal en relación a la capacidad de carga de un destino. Los turistas que realizan este tipo de turismo poseen una motivación en particular basada en el interés por un evento deportivo, artístico y/o cultural determinado, la valorización de aspectos culturales de un territorio, la conservación de modos de vida tradicionales, interpretación y conservación de la naturaleza, y la práctica de deportes aventura" (Pacheco et al., 2011: 51).

\section{Enfoque del ensayo}

El objetivo de este ensayo es proponer principios para el desarrollo de lineamientos estratégicos para la IP del TIE en la Región de Los Lagos y particularmente en Patagonia Verde como destino turístico de interés. Se identifican las barreras de la IP en las principales áreas naturales protegidas de la Región de Patagonia-Los Lagos, así como experiencias que han aplicado técnicas y recursos de la IP en el desarrollo de nuevos productos turísticos, favoreciendo su desarrollo y puesta en valor. Finalmente, se reflexiona sobre la filosofía de la IP respecto a la vinculación entre habitante/anfitrión y visitante/ turista. 
Se proponen tres principios fundamentales para el desarrollo de la IP en la Región de Los Lagos, con el objeto de fortalecer la promoción de los destinos y mejorar la experiencia in situ de los visitantes. En estos principios se sustentan las reflexiones y aproximaciones a la temática en este ensayo, los cuales se describen a continuación.

A- Planificación Turística Integral: Se requiere que la planificación turística a nivel regional se materialice en una carta de navegación oficial para el turismo para el mediano y largo plazo. Para ello son necesarios planes o estrategias de desarrollo que incluyan planes maestros de IP. Estos pueden ser aplicables para mejorar la experiencia turística y fomentar el respeto y buen comportamiento en las áreas naturales protegidas, como también para desarrollar participativamente planes de promoción de sitios y mejorar todas las experiencias turísticas del territorio, que involucren a guías, tour operadores y residentes locales que requieren comunicar mejor su vínculo con el patrimonio local y con los visitantes.

B- Promoción Integral: Se requiere desarrollar una promoción integral, que involucre al arte, sea participativa y representativa de la identidad territorial. Estos elementos son esenciales a la hora de hacer tangible una experiencia turística; recordarla y hacerla una experiencia de vida, que si es parte de un suceso positivo puede generar recomendaciones exponenciales (un fenómeno ampliamente estudiado en la psicología cognitiva del turismo). Es fundamental en los destinos del TIE diseñar mapas interpretativos, contar con señalética caminera confiable y en buen estado, miradores y atractivos con paneles interpretativos y que también existan artesanías, esculturas y otros productos con identidad local, etc. La experiencia turística se enriquece cuando existen expresiones artísticas y/o culturales en los territorios, que los hagan más atractivos para visitar. Es fundamental impulsar espectáculos y activaciones que involucren el teatro, la gastronomía, la literatura, la música, la pintura, la producción audiovisual, la danza y las artes de interpretación del paisaje (paisajismo). Todo esto permite una trazabilidad social que logra interpretar el mismo origen de una producción local.

C- Comunicación Temática: Se requiere comunicar las mismas experiencias a través de mecanismos de promoción y difusión. Se plantea la necesidad de contar con una promoción participativa, que involucre a los actores locales del turismo en la comunicación de experiencias bien tematizadas, esto quiere decir que sean TORA: Temáticas, Ordenadas, Relevantes y Amenas (Sam Ham, 2014). A la vez, impulsar la IP y vincular un enfoque integral para el enriquecimiento de las experiencias turísticas. No son suficientes los esfuerzos si no se logra comunicarlos bien a otros que aún no conocen estas experiencias locales. En ese sentido, la promoción en medios escritos, virtuales y otros vinculados al TIE es un aspecto fundamental para hacer visibles las experiencias planificadas de los destinos de la Región de Los Lagos. Todos los planes de IP deben contar con una estrategia 
de difusión en medios que aborde la misma cuestión temática que plantea la IP, de acuerdo con la audiencia o segmento objetivo, para llamar la atención, informar y despertar el interés de visitantes potenciales previamente estudiados.

\section{Metodología}

El trabajo de campo, de donde se extraen los principales puntos de vista de este ensayo, está basado en una investigación acción en la que se logró identificar la vinculación de los actores turísticos con productos que contemplaran la utilización de recursos patrimoniales y de técnicas relacionadas a la IP en las cuatro provincias de la Región de Los Lagos: Osorno, Llanquihue, Chiloé y Palena. Se realizaron entrevistas mediante una muestra por conveniencia creada según consultas a actores clave, cuyos resultados arrojaron una evidente necesidad de nuevos productos turísticos que abordaran la creación de experiencias vinculadas al turismo patrimonial (natural y cultural). Así, se identificó la brecha de que no existen suficientes operadores locales y organismos públicos involucrados en la generación de productos que pongan en valor el patrimonio natural y cultural de sus comunas y provincias.

Se realizó un trabajo de campo entre abril de 2012 y mayo de 2013, se logró identificar gran parte de los atractivos y de los productos turísticos que se vienen desarrollando, donde todos, sin excepción, contemplan el patrimonio natural y cultural como elementos diferenciadores y como atractivos básicos para la generación de una oferta de TIE, generando la gran interrogante desde el campo del trabajo en IP: ¿Cómo vincular la IPal desarrollo de nuevas estrategias depromoción y difusión de experiencias de TIE?

Se entrevistó a líderes de agrupaciones y gremios del turismo, se realizaron reuniones con instituciones públicas como el Servicio Nacional del Turismo (SERNATUR, municipios e instituciones de fomento productivo, y todos, sin excepción, aportaron la visión de una profunda necesidad de superar la brecha de promoción turística y crear experiencias turísticas de calidad. Se compartió la visión de necesidad de un marketing turístico con una mirada planificada y responsable sobre la búsqueda de una experiencia turística coherente y a la altura de los estándares internacionales, abordándose desde el paradigma de lo que es una construcción colectiva del destino y desde una puesta en valor del patrimonio en coherencia con su estado de conservación; tomando la responsabilidad de planificar el turismo desde el delicado equilibrio de considerar el patrimonio cultural y natural del territorio como un recurso o un bien público altamente vulnerable $\mathrm{y}$ que presenta evidentes necesidades de cuidado y protección. 
Se realizaron talleres participativos en las cuatro provincias de la Región de Los Lagos, en marco al proyecto NODO TIE Patagonia Los Lagos ejecutado por el Departamento de Gobierno y Empresa de la Universidad de Los Lagos, y que es cofinanciado por la Corporación de Fomento a la Producción (CORFO), donde se buscó empoderar a los líderes locales y comunales en su organización $\mathrm{y}$ en sus planes de trabajo orientados a la promoción turística, desde la asociatividad y la visión de la planificación turística local; ambos aspectos fundamentales para la implementación adecuada de las técnicas de la IP al TIE.

Gracias al trabajo con las organizaciones gremiales locales se identificaron productos de TIE y se caracterizaron sus formas de trabajar la IP, arrojando como resultado la evidente necesidad de aplicar planes de IP específicos por productos, comunas y territorios de interés patrimonial. La gran mayoría carece de un guión interpretativo tematizado y de las herramientas técnicas más relevantes para garantizar la calidad de la puesta en valor in situ de los recursos turísticos (Castaing et al., 2013).

\section{Resultados}

\section{Principios de la Interpretación del Patrimonio en la Experiencia de Viaje}

¿Por qué viajamos? ¿Qué es viajar realmente? Son dos preguntas simples pero muy fundamentales para comprender la base de las tan anheladas motivaciones de un viaje, (especialmente para el desarrollo de las a veces complejas estrategias de marketing en el turismo), por lo que la búsqueda de una respuesta también simple nos puede llevar a la idea de que viajamos porque queremos encontrarnos con algunas experiencias universales y conocidas como: un respiro, un escape, tranquilidad, aprender, conocer. Todas motivaciones básicas inherentes a un ser humano con capacidad ociosa, ya que si le preguntamos a ese mismo ser humano por qué quiere ir a ese destino determinado con el que ha soñado, nos encontraremos con la promesa de una de esas experiencias trascendentes en su vida.

De esta forma nos preguntamos ¿cuáles son los elementos humanos, vitales o culturales, que universalmente materializan estas experiencias trascendentes? ¿Cómo logramos entregar respuestas a una búsqueda que es personal y que involucra aspectos elementales en todo ser humano sin importar su idioma, su cultura o sus creencias? La IP viene a unir con intuición y metodología algunos cabos sueltos entre aspectos que hoy son tan relevantes para el turismo como: la experiencia, el patrimonio comunitario y ancestral, el desarrollo sustentable, 
la gestión integrada de los destinos y la creación de nuevos productos turísticos asociativos por parte de las comunidades locales.

Los Principios de la Interpretación del Patrimonio fueron dictados por Freeman Tilden en su obra Interpreting our heritage (Interpretando nuestro Legado) en 1957, los que señalan:

1.- Cualquier interpretación que de alguna forma no relacione lo que se muestra o describe con algo que se halle en la personalidad o en la experiencia del/de la visitante, será estéril.

2.- La información, tal cual, no es interpretación. La interpretación es revelación basada en información, aunque son cosas completamente diferentes. Sin embargo, toda interpretación incluye información.

3.- La interpretación es un arte, que combina otras muchas artes, sin importar que los materiales que se presentan sean científicos, históricos o arquitectónicos. Cualquier arte se puede enseñar en cierta forma. El objetivo principal de la interpretación no es la instrucción, sino la provocación.

4.- La interpretación debe intentar presentar un todo en lugar de una parte, y debe estar dirigida al ser humano en su conjunto, no a un aspecto concreto.

5.- La interpretación dirigida a niños y niñas (digamos, hasta los doce años) no debe ser una dilución de la presentación a las personas adultas, sino que debe seguir un enfoque básicamente diferente. Para obtener el máximo provecho, necesitará de un programa específico.

Desde estos cinco principios se pueden extraer técnicas y crear bases para el desarrollo de metodologías de planificación participativa y de desarrollo teórico y práctico de nuevos productos turísticos de intereses especiales; desarrollando el tipo de experiencia diferenciadora que se desea crear y a quién está dirigida (público objetivo, target o segmento de mercado).

Al involucrar una visión de encadenamiento productivo, de destino turístico y de una promoción de destino asociativa y tematizada, se pueden abordar estrategias y metodologías asertivas relacionadas con el desarrollo de productos promocionales y elementos que constituyan la experiencia que puede ofrecer un destino: desde la necesidad de informar a la fundamental necesidad de comunicar y provocar en la audiencia el interés en una imagen del destino que refleje la 
verdadera cohesión de elementos que componen la oferta turística coherente una comunidad local.

El territorio, sus relatos, el paisaje y las culturas que lo constituyen pasan a conformar el dinamismo de un legado vivo, en permanente movimiento y en comunicación directa con los actores locales, que ejercen su derecho de ser anfitriones, a la vez que se interesan en encontrar estos elementos que conectan la i nformación temática con la experiencia de los visitantes.

La perpetua interrogante de identificar el patrimonio como un recurso o un bien de consumo versus la necesidad de ponerlo en valor y conservarlo, pasa a ser un fruto maduro en esta búsqueda de equilibrio integrativo, ya que la pertenencia y los derechos sobre este legado son de la misma comunidad que ejerce su voluntad de abrirse a la actividad y al mercado turístico como una forma de cerrar un círculo virtuoso; viendo el turismo como un medio y no como un fin en sí mismo, como una herramienta para "recordar" y valorar de manera armónica y sustentable lo que los propios habitantes del territorio habían olvidado producto de la devaluación económica y el deterioro socioambiental del mismo patrimonio, hoy poniéndolo en valor y logrando su categorización como atractivo turístico bajo temáticas organizadas, relevantes y amenas (Sam Ham, 2014).

La intervención y la transformación de estos elementos patrimoniales son comprensibles desde el punto de vista de la provocación, un elemento clave desde los principios de Tilden. La información debe ser fidedigna, pero la incorporación de nuevos elementos en la sicología del relato, bajo la intención de provocar y despertar el interés por el legado y el patrimonio desde la subjetividad del intérprete, viene a ser fundamental para atraer a la audiencia y develar el misterio de lo olvidado y lo oculto detrás de lo que es simple información o simples hechos aislados, una flexibilidad de criterio comunicacional que no suele ser incorporada al presentarse como resultado de un trabajo planificado y con un desarrollo metodológico científico aplicado, el que pueda ser usado en estrategias de desarrollo o más bien políticas públicas.

En la Región de Los Lagos se han desarrollado productos y atractivos turísticos basados en estos principios, ya sea en forma consciente y planificada, así como de manera espontánea e intuitiva, donde vemos casos de: rutas culturales, parques temáticos, centros de interpretación y sitios arqueológicos, etcétera.

Es así como surge la pregunta ¿quién es el responsable de que se apliquen los principios de la IP a escala regional? Muchas veces este tipo de pregunta parece ser fácil de responder: la responsabilidad es compartida siempre entre un conjunto 
de actores, muchas veces también incluyendo a los visitantes. No cabe duda que a nivel regional hacen falta planes de IP de distintos atractivos como, por ejemplo, nuestros parques, atractivos patrimoniales, reservas y monumentos nacionales.

Los planes de la IP responden a procesos, fases comunicacionales y también sicológicas, que a su vez son aplicables en cualquier estrategia de promoción de un destino. Todo plan de IP debería tratar de responder las siguientes preguntas, y contener al menos las siguientes etapas que se describen en el Cuadro 1.

\section{Cuadro 1. Preguntas básicas para las distintas etapas de la planificación en IP:}

\begin{tabular}{|l|l|}
\hline $\begin{array}{c}\text { Etapas de la Planificación en } \\
\text { Interpretación del Patrimonio }\end{array}$ & \multicolumn{1}{|c|}{ Preguntas Básicas de Interpretación } \\
\hline 1.- Catastro del patrimonio & $\begin{array}{l}\text { ¿Qué es patrimonial en términos oficiales? ¿Cuáles de } \\
\text { estos elementos son de interés y qué necesidades tienen? }\end{array}$ \\
\hline 2.- Análisis de los actores & $\begin{array}{l}\text { ¿Qué entienden cómo patrimonial? ¿Qué necesidades } \\
\text { tienen sobre su patrimonio? }\end{array}$ \\
\hline 3.- Definición de objetivos & $\begin{array}{l}\text { ¿Qué se desea lograr? ¿Qué se debe recordar y/o } \\
\text { proteger? }\end{array}$ \\
\hline 4.- Técnicas y canales & $\begin{array}{l}\text { ¿Cómo se comunicará el/los mensaje(s)? ¿Qué medios se } \\
\text { utilizarán? ¿Cómo se provoca? }\end{array}$ \\
\hline 5.- Plan y programas de gestión & ¿Qué actividades? ¿Dónde? ¿Quién? ¿Cuándo? \\
\hline 6.- Detalle de recursos a utilizar & $\begin{array}{l}\text { ¿Qué recursos se utilizarán? ¿Cuáles son humanos } \\
\text { (técnicas) y cuáles son materiales? ¿Qué costos tienen? } \\
\text { ¿Qué fuente de financiamiento es adecuada? }\end{array}$ \\
\hline $\begin{array}{l}\text { 7.- Indicadores y técnicas de } \\
\text { evaluación del fenómeno }\end{array}$ & $\begin{array}{l}\text { ¿Es una experiencia temática, ordenada, relevante, amena } \\
\text { e integral? ¿Cómo puedo desarrollar indicadores en } \\
\text { términos de la percepción de los mismos actores? }\end{array}$ \\
\hline
\end{tabular}

\section{La Interpretación del Patrimonio en Áreas Naturales Protegidas del Estado}

En la Región de Los Lagos nos podemos encontrar con áreas protegidas del Sistema Nacional de Áreas Silvestres Protegidas del Estado (SNASPE) en diversos grados de protección y desarrollo; uno de los aspectos más interesantes tiene que ver con la diversidad de áreas protegidas y la cantidad de visitas que estas reciben. Por ejemplo, el Parque Nacional Vicente Pérez Rosales es uno de los más visitados del país.

“Durante el año 2012, las diferentes Áreas Silvestres Protegidas de la Región de Los Lagos recibieron la visita de 514.248 personas. De ellas, el Parque Nacional Vicente Pérez Rosales, con sus grandes íconos turísticos del sur de Chile, los 
Saltos del Petrohué y el volcán Osorno, recibió 332.334 visitas; el Parque Nacional Puyehue, 133.037, y el Parque Nacional Chiloé, 27.049 visitas" (CONAF, 2012). Divididos en monumentos, reservas y parques según la Ley 18.362 de 1984, se establece una importante distinción por territorios, grados de protección y administración de sus recursos, dividiéndolos en: Parques Nacionales: Área de gran extensión con ambientes y hábitats únicos y representativos de la diversidad biológica nacional, los cuales se han mantenido prácticamente inalterados por la acción humana y que poseen capacidad de auto perpetuarse. Sus especies de flora y fauna, además, tienen gran importancia e interés para las ciencias y la educación. El objetivo de los parques nacionales son la preservación de estos ambientes y la compatibilización con actividades educativas, investigativas y recreativas.

Reservas Nacionales: Área de menor extensión que el parque nacional, en la que son necesarios su conservación y cuidado debido al peligro de que este ambiente único pueda sufrir cambios irreparables y dañar el medio ambiente y el bienestar de la comunidad.

Monumentos Naturales: Áreas de superficie reducida y específica en torno a un lugar geográfico de gran importancia arqueológica, cultural o natural. Se caracterizan por la presencia de sitios geológicos únicos o de especies nativas de flora y fauna.

Así, en la Región de Los Lagos se destacan el Parque Nacional Vicente Pérez Rosales (107.000 ha) como uno de los más visitados; el Parque Nacional Alerce Andino (39.255 ha), con interesantes y variados senderos de trekking y hiking; el Parque Nacional Chiloé (43.057 ha), fundamental como reserva de la biodiversidad en la Isla Grande; el Parque Nacional Puyehue (43.057 ha), con sus termas y refugios invernales; y en Patagonia Verde el Parque Nacional Hornopirén (48.232 ha), con bosques pretéritos, y el Parque Nacional Corcovado (209.623 ha), uno de los más recientes y australes (con acceso restringido y con instalaciones precarias).

Un aspecto de gran relevancia son las tierras donadas por la Fundación Pumalín del filántropo Douglas Tompkins dónde un comunicado de la Presidencia de Chile señala que es "la mayor donación privada de tierras de la historia"- son más de 407 mil hectáreas que servirán para crear tres parques nacionales: Pumalín, Melimoyu y Patagonia. Solo en el territorio de Patagonia Verde se ampliarán otros tres parques ya existentes: Hornopirén, Corcovado e Isla Magdalena que serán parte de una denominada Red de Parques de la Patagonia (con 4,5 millones de hectáreas entre la Región de Los Lagos y de Magallanes). 
"Un turismo bien gestionado puede ayudar también a proteger o restaurar el patrimonio cultural de una comunidad o una región. Las áreas protegidas tienen un papel importante que desempeñar en relación con el patrimonio construido" (Eagles et al., 2002:28).

Si bien es cierto que hay una gran extensión de áreas protegidas en la región, podemos considerar que la oferta de su planta turística (servicios básicos que incluyen desde aspectos como los baños o los servicios de alimentación a la misma oferta de interpretación) en muchos casos es deficiente, ya que los recursos con que cuenta la Corporación Nacional Forestal (CONAF), como principal responsable de esta gestión a escala nacional, son siempre muy limitados para la implementación de infraestructura y para aspectos tan relevantes en la IP como: la señalética, los paneles interpretativos, los mapas interpretativos, los guías intérpretes ambientales, los centros de interpretación y la publicación de herramientas como guías y folletería interpretativa, entre otros recursos relacionados.

Factores clave son la cantidad de guardaparques y la cantidad de recursos aplicados a estas áreas protegidas en sus Planes de Interpretación (y en gestión local de estas áreas). La primera reflexión apunta al personal en contacto calificado en este tema: la dotación de guardaparques en todo el territorio Chileno es de 432 funcionarios(as), lo que muchas veces no alcanza a cubrir la totalidad de las áreas protegidas en Chile, considerando que es el $19 \%$ de la superficie total del país, como también debido a la cantidad y diversidad de funciones que deben cumplir. Para la especialidad de interpretación ambiental, por lo tanto, solo queda un número muy reducido de profesionales que puedan entregar un guiado interpretativo y que puedan colaborar con verdaderos planes de IP en comunidades locales.

Un punto crítico, desde el punto vista del desarrollo de los planes de IP en las zonas de amortiguación de los parques nacionales y en los mismos consejos consultivos locales, radica en la orientación interpretativa que logran dar los mismos guardaparques gracias a las capacitaciones a las que han asistido. Así, "los cursos y capacitaciones durante el último año han sido sobre: legislación ambiental, evaluación de impacto ambiental, conservación de la biodiversidad e inglés básico, y solo 16 del total de guardaparques de la región se han capacitado desde septiembre del año 2012 a octubre de 2013 (NODO TIE Patagonia Los Lagos 2013). 
Últimamente, Chile ha sido evaluado como uno de los 10 países (de un total de 124) que menos invierten en sus áreas protegidas. Anthony Waldron, investigador de la Universidad de Georgia y de la Estatal de Santa Cruz, explicó en la prensa chilena que el cálculo estadístico arroja que Chile debería invertir 55,44 millones de dólares más de lo que gasta al año. Waldron sostiene que un informe que el Programa de las Naciones Unidas para el Desarrollo (PNUD) lanzó en 2010 indica que Chile gasta poco más de 60 centavos de dólar por hectárea en sus áreas protegidas, unos 325 pesos chilenos, lo que comparado con el promedio para Latinoamérica y el Caribe es muy poco (US\$ 1,95 aproximadamente), y con el gasto de Argentina (US\$ $8,56)$ o de países más pobres, como Guatemala, Nicaragua y Honduras, que gastaban entre tres y cuatro dólares por hectárea (Espinoza, 2013).

Las comunidades locales y los guardaparques requieren con urgencia adquirir herramientas y formación en IP, así como de instancias de planificación donde se puedan generar propuestas participativas de promoción y tematización de la experiencia pensada en los visitantes. El desarrollo de estrategias de promoción participativa es una forma de integrar la IP a la promoción turística de las comunidades con modelos de desarrollo local.

\section{Acciones y Técnicas Aplicadas de Interpretación del Patrimonio en la Región de}

\section{Los Lagos}

Tanto museos, centros de interpretación ambiental, operadores de turismo aventura, como diversos prestadores de servicios turísticos han desarrollado técnicas y métodos que se pueden enmarcar como actividades y acciones de IP; bajo la distinción de lo que es endógeno, comunitario e integrado.

El trabajo fundamental es involucrar a los actores locales en la gestión de sus atractivos, logrando jerarquizarlos $\mathrm{y}$, finalmente, identificando su grado de desarrollo, vulnerabilidad y calidad desde el punto de vista turístico, lo que permite que la misma comunidad logre planificar acciones con miras a determinar cómo protegerlos, cuáles utilizar en un determinado circuito $\mathrm{y}$, en definitiva, cuáles promocionar como elementos integradores de una nueva oferta turística experiencial. En el Cuadro 2 se presentan los atractivos y productos turísticos que han incorporado técnicas de IP en la Región de Patagonia-Los Lagos sin necesariamente implicar el desarrollo de un Plan Maestro. 
Cuadro 2. Patrimonio de uso turístico con técnicas de IP en la Región de Los Lagos.

\begin{tabular}{|c|c|c|}
\hline $\begin{array}{c}\text { Atractivos y productos } \\
\text { turísticos con técnicas de IP }\end{array}$ & Lugar & Estado \\
\hline 1.- Parque Ayaltué & $\begin{array}{l}\text { Comuna de Puerto Montt - } \\
\text { Provincia de Llanquihue }\end{array}$ & Planificación endógena \\
\hline $\begin{array}{l}\text { 2.- Parque Ecológico y } \\
\text { Mitológico de Chiloé }\end{array}$ & $\begin{array}{l}\text { Comuna de Ancud - } \\
\text { Provincia de Chiloé }\end{array}$ & Planificación endógena \\
\hline $\begin{array}{l}\text { 3.- Museo El Colono de } \\
\text { Frutillar }\end{array}$ & $\begin{array}{l}\text { Comuna de Frutillar - } \\
\text { Provincia de Llanquihue }\end{array}$ & $\begin{array}{l}\text { Planificación endógena } \\
\text { (Museología UACH) }\end{array}$ \\
\hline $\begin{array}{l}\text { 4.- Parque Pleistocénico } \\
\text { Chuyaca }\end{array}$ & $\begin{array}{l}\text { Comuna de Osorno - } \\
\text { Provincia de Osorno }\end{array}$ & $\begin{array}{l}\text { Planificación integrada } \\
\text { (Mesa de Turismo) }\end{array}$ \\
\hline $\begin{array}{l}\text { 5.- Monumento Natural } \\
\text { Puñihuil }\end{array}$ & $\begin{array}{l}\text { Comuna de Ancud - } \\
\text { Provincia de Chiloé }\end{array}$ & $\begin{array}{l}\text { Planificación comunitaria } \\
\text { (Operadores locales y } \\
\text { CONAF en coordinación) }\end{array}$ \\
\hline 6.- Catedral de Osorno & $\begin{array}{l}\text { Comuna de Osorno - } \\
\text { Provincia de Osorno. }\end{array}$ & Planificación integrada \\
\hline
\end{tabular}

Se observan planificaciones integradas, endógenas y comunitarias de atractivos y productos turísticos que han incorporado técnicas de IP. Los planes endógenos responden a iniciativas individuales que no han logrado generar mayor sinergia o vinculación con otros actores y relatos de los territorios donde se localizan. Los planes integrados responden a bienes comunes y/o colectivos que incorporan en su planificación y gestión a distintos actores públicos y privados así como a profesionales que aplican lineamientos de IP. Los planes comunitarios responden a patrimonios colectivos que son gestionados en colaboración, pero dónde se interpretan algunos de sus rasgos o elementos patrimoniales. En la gran mayoría de las iniciativas identificadas no se observa mayor participación de las comunidades locales, siendo un gran desafío incorporar en la gestión del patrimonio y el uso de IP a residentes locales y habitantes que conocen in situ la historia y cultura locales. Por la misma baja participación o vinculación de la comunidad local en el rescate y conservación del patrimonio, los productos con planes integrados, tal como el Monumento Natural de Puñihuil, sea su propio trabajo de turismo comunitario como su Centro de Interpretación, son subutilizados en su verdadero potencial interpretativo y turístico, pero gracias a su planificación comunitaria y a su apalancamiento con diversas iniciativas públicas y privadas tiene muchas posibilidades de continuar desarrollándose. Un resultado a destacar bajo este estudio fenomenológico es la carencia de iniciativas que integren a la IP en la Provincia de Palena, conocido como el territorio y destino turístico de Patagonia Verde (al norte de la Patagonia Chilena). 
Un plan de gestión integral desde el fenómeno social del turismo local no debe dejar de lado el factor distintivo de lo que se logra definir y mapear en la visión cotidiana de un habitante del sur de Chile, tanto en las denominaciones de origen como sobre las experiencias diferenciadoras que comprenden una oferta coherente con la calidad turística y el patrimonio local. Sin importar si la visión interpretativa del fenómeno adquiere su sistematización metodológica desde herramientas de la psicología cognitiva, desde la sociología o de campos más transpersonales u holísticos, el desarrollo metodológico integrativo es fundamental para influir en el sistema turístico, en sus medios interpretativos y para colaborar en la creación de experiencias guiadas y auto-guiadas de calidad

\section{Conclusiones}

Toda experiencia de viaje es una relación entre el visitante, el anfitrión, el patrimonio cultural y natural. En donde las interpretaciones intangibles y los relatos de cada guiado generan una temática sobre el lugar que se visita.

A- Una necesidad evidente en el desarrollo turístico local y regional es la que se puede observar en la "sed" por nuevas herramientas y nuevos recursos que ayuden en la labor de enriquecer la experiencia turística de los visitantes del sur de Chile; sabiendo que en los recursos del arte se pueden obtener una infinidad de aspectos que desde la gestión turística cumplen una labor sinérgica por crear valor identitario y cultural dentro de las mismas comunidades locales. Un desafío regional es llegar a territorios donde la IP es casi desconocida y es crítica en la planificación de la infraestructura y la misma gestión de los servicios que ofrece la planta turística local a sus visitantes.

B- El turismo es una herramienta y no un fin en sí mismo, al igual que la IP puede sernos útil para rescatar y conservar nuestro patrimonio, siempre y cuando se pretenda generar beneficios a las comunidades locales que trabajan con la visión que tienen organizaciones colaborativas como son las cooperativas $u$ otras organizaciones de base, no tan solo económicos como postula la visión tradicional del turismo como industria, sino también beneficios culturales y socioambientales a las comunidades receptoras.

C- Las futuras estrategias de desarrollo turístico regional o políticas regionales de turismo deben incorporar planes maestros de IP que logren poner en valor atractivos turísticos actuales como también potenciales, así como también las denominaciones de origen que vinculen a su patrimonio comunitario. Todos los parques nacionales de la región y del país debieran contar con planes de IP, que logren poner en valor sus atractivos y aumentar sus grados de protección y conservación. Aspecto que podría verse 
fortalecido en el mediano plazo si el Ministerio de Medio Ambiente logra implementarlo en su nueva función de administrar las Áreas Protegidas del Estado, en especial considerando la reciente incorporación de la Red de Parques de la Patagonia, conjunto de 4,5 millones de hectáreas.

D- La promoción turística regional debe ser de carácter participativo, debido a que es importante considerar las visiones de las comunidades locales y residentes que se dedican al turismo, porque son ellos quienes viven la realidad integral de sus destinos. La promoción no solo debe realizarse por técnicos encerrados entre cuatro paredes, sino también los microempresarios, las cooperativas de productores locales y la misma comunidad organizada pueden proponer elementos de importancia para a dar a conocer sus territorios y tematizarlos. Se considera que para los efectos de la promoción participativa la IP es una técnica fundamental, que a través de herramientas como mapas, artesanía identitaria, paneles, señalética, folletería y souvenirs temáticos, material audiovisual como audioguías, etc., puede tangibilizar la realidad de las experiencias, realizar una promoción respetuosa y coherente, como también provocar, orientar $\mathrm{y}$ sensibilizar a los turistas respecto al patrimonio.

E- Es preciso contar con una voluntad política y técnica de la institucionalidad pública interviniente en el turismo y la cultura en la Región de Los Lagos como en sus provincias y comunas, para potenciar el arte y la puesta en valor del patrimonio mediante la creación de planes maestros de IP. Es preeminente que el sector público fomente el diálogo con el arte y la cultura, dados la importancia para el desarrollo de los mismos residentes locales, el cuidado del patrimonio y el respeto de los visitantes en los destinos. Se requiere impulsar las actividades artísticas y culturales, a través de eventos u otros desarrollos temáticos y coordinados. Respetando al patrimonio local de las comunidades y también a los visitantes, en el descubrimiento de los saberes locales y demás tradiciones que dan origen a su patrimonio, creando así un vínculo tangible en los destinos turísticos con aspectos integrales tan clásicos para Sudamérica como el buen vivir, o tan simples como la búsqueda de la misma felicidad de las comunidades receptoras. Con ello se enriquece la experiencia, pero al mismo tiempo se otorga un sustento auténtico en los territorios donde se pretende rescatar y conservar el patrimonio natural y cultural. Asimismo, la realización de actividades culturales son una fundamental alternativa para combatir la estacionalidad cuando logran vincularse a un turismo que fomenta la colaboración, sobre todo en meses de invierno donde es necesario motivar la llegada de los visitantes a través de estrategias de promoción y diversificación productiva que involucren a las comunidades locales de territorios amenazados por brechas de orden sectorial. Un ejemplo claro puede ser la escasa conectividad y la baja inversión en infraestructura interpretativa para visitantes, tomando a Patagonia Verde como un caso crítico en este sentido. 


\section{VI.Bibliografía}

Boullon, R. (2003). Ecoturismo: Sistemas naturales y urbanos. Ediciones Turísticas, tercera Edición.

Castaing, J (2015). La experiencia del terroir en un viñedo en Chile. Boletín de Interpretación $\mathrm{N}^{\mathrm{o}} 32$, septiembre. Asociación para la Interpretación del Patrimonio.

Castaing, J.; Pacheco, G., y Vera, J. (2013). La interpretación del patrimonio en la Región de Los Lagos. Anales VII Congreso de la Sociedad de Investigadores de Turismo de Chile (SOCIETUR). Iquique, Chile. CONAF (Corporación Nacional Forestal). (2012). Estadísticas de visitas a Áreas Naturales Protegidas del Estado.

Eagles,P.F.J.; McCool,S.F.,y Haynes, C.D.(2002). Turismosostenibleenáreas protegidas. Directrices de planificación y gestión. Preparado para el Programa de las Naciones Unidas para el Medio Ambiente (PNUMA), la Organización Mundial del Turismo (OMT) y la Unión Internacional para la Conservación de la Naturaleza (UICN).

Espinoza, C. (2013). Estudio ubica a Chile entre los 10 países que menos invierten en biodiversidad. Diario La Tercera, 3 de julio. Edición impresa. Santiago, Chile.

González, K. (2017). Donación de Tompkins permitirá crear la Red de Parques de la Patagonia. Diario La Tercera, 16 de Marzo. Edición digital. Santiago, Chile.

Morales, J.; Fernández, B. et al. (2007). La interpretación del patrimonio en la Argentina: Estrategias para conservar y comunicar nuestros bienes naturales y culturales. Buenos Aires: Administración de Parques Nacionales.

Morales, J. y Guerra F. (2016). Pautas para la interpretación de lugares y rasgos patrimoniales; Oficina de Medio Ambiente y Patrimonio de Nueva Gales del Sur (traducción AIP), Australia.

Hamish, M. (2009). Interpretación: ¿Profesión, disciplina, arte o ciencia? Boletín de Interpretación $\mathrm{N}^{\circ} 21$, septiembre. Asociación para la Interpretación del Patrimonio.

Ham, Sam H. (2007). ¿Puede la Interpretación marcar una diferencia? Respuestas a cuatro preguntas de psicología cognitiva y del comportamiento. Boletín de Interpretación número 17: 10-16. Asociación para la Interpretación del Patrimonio, España.

Ham, Sam H. 2006. La psicología cognitiva y la interpretación: síntesis y aplicación. Boletín de Interpretación número 15: 1421. Asociación para la Interpretación del Patrimonio, España.

Ham, Sam H. 2014. Un poco de psicología ayuda mucho. Boletín de Interpretación número 29: 17-20. Asociación para la Interpretación del Patrimonio, España.

Ham, Sam H. 2014. Interpretación - Para marcar la diferencia intencionadamente. Edita: Asociación para la Interpretación del Patrimonio, España.

Morales, J. (2001). Guía práctica para la interpretación del patrimonio. El arte de acercar el legado natural y cultural al público visitante. Dirección General de Bienes Culturales, Junta de Andalucía, y TRAGSA. Segunda edición, España. 
Morales, Jorge. 2005. Bases para la capacitación en interpretación del patrimonio. Boletín de Interpretación número 12: 2427. Asociación para la Interpretación del Patrimonio, España. Morales, Jorge.; y Ham, Sam H. 2008. ¿A qué interpretación nos referimos? Boletín de Interpretación número 19: 4-7. Asociación para la Interpretación del Patrimonio, España.

NODO TIE Patagonia Los Lagos (2013). Guardaparques de la región: Interpretación patrimonial, una tarea pendiente. Octubre 2013.

Pacheco, G.; Henríquez, C.; Sampaio, C., y Oyarzún, E. (2011). Encadenamientos socioproductivos y ecosocioeconomía de las organizaciones: análisis propositivo para el Turismo de Intereses Especiales (TIE) en el territorio lacustre de la Región de La Araucanía.

Pacheco, G. y Castaing J. (edit) 2014. La gestión de Destinos en la Región de Los Lagos: Una guía para el turismo de intereses especiales. Proyecto Nodo Tie Patagonia Los Lagos. Universidad de Los Lagos.

Kohl, Jon (2015). Estándares más holísticos para la interpretación del siglo XXI. Boletín de Interpretación número 30 España- Marzo de 2015.

Stevens, J., \& Bruggendieck, M. (2003). El darse cuenta (1era ed.). Santiago de Chile: Cuatro vientos.

Tilden, F. (1957). Interpreting our heritage. The University of North Carolina Press, EE.UU Tilden, F. (1968). The Fifth Essence. The National Park Trust Fund Board; 1st edition (1968), EE.UU

Torres, M. (2012). El diseño en la comunicación del patrimonio cultural. Tesis de la Facultad de Diseño y Comunicación, Universidad de Palermo, Argentina. 